\title{
Analysis on Construction and Management of Laboratory in Independent Colleges under the Situation of Innovation and Entrepreneurship Education
}

\author{
Kequan Feng \\ Laboratory and Asset Management Office \\ Zhuhai College of Jilin University \\ Zhuhai, Guangdong, China
}

\author{
Yaomin Mei \\ Scientific Research Office \\ Zhuhai College of Jilin University \\ Zhuhai, Guangdong, China
}

\author{
Zhiqiang Wang \\ Laboratory and Asset Management Office \\ Zhuhai College of Jilin University \\ Zhuhai, Guangdong, China
}

\begin{abstract}
Under the situation that colleges vigorously carry out innovation and entrepreneurship education, integrate characteristics of construction and management of laboratory in independent colleges, make use of capital of innovation and entrepreneurship education outside school and requirements of innovation and entrepreneurship education for technical talents, equipment and sites of laboratory in colleges, promote the construction and management of laboratory in independent colleges. Independent colleges improve service quality of laboratory and further provide powerful guarantee for innovation and entrepreneurship education through strengthening connotation of construction and management of laboratory, integrate innovation and entrepreneurship education with construction and management of laboratory, in order to achieve the purpose of mutual promotion, mutual benefit and win-win result.
\end{abstract}

Keywords-innovation and entrepreneurship education; independent college; construction and management of laboratory

\section{INTRODUCTION}

As important place for innovation and entrepreneurship education in colleges, laboratory provides powerful guarantee in aspects such as laboratory equipment and experimental technical support for innovation and entrepreneurship education in colleges. The cultivation quality of talents in innovation and entrepreneurship depends on the level of construction of laboratory to a large extent. [1] Independent colleges take the cultivation of applied talents as the goal. Laboratory is the main place for colleges to cultivate talents, innovate in technology and serve the society and the important position to create brand of college. [2] Under the situation that colleges vigorously carry out innovation and entrepreneurship education, the construction of laboratory should fully consider school-running orientation and characteristics of colleges, which help to cultivate students' ability of innovation and entrepreneurship and improvement of comprehensive quality. Meanwhile, it is necessary to improve the management quality of laboratory and use high quality management level of laboratory to provide better service for innovation and entrepreneurship education.

\section{CURRENT SITUATION OF CONSTRUCTION AND}

\section{MANAGEMENT OF LABORATORY IN INDEPENDENT COLLEGES}

After more than ten years of growth, the scale of construction of independent colleges becomes stable. The strategic target of development turns from scale development to connotative development. The large-scale construction period of laboratory has been already over. During construction period, it refers to the experience of many domestic colleges, takes the satisfaction of undergraduate teaching as the purpose, cultivation of applied talents as the objective, has clear construction localization and relatively flexible construction mode, and carries out in the way of centralized planning and stage construction, with relatively reasonable layout. As a whole, it has clear construction thoughts, relatively reasonable configuration and relatively high investment benefits. At present, the capital investment of laboratory mainly focuses on increase of a small amount of equipment, professional corollary equipment, and daily consumption of experiment as well as maintenance of experimental equipment.

After many years of development and continuous perfection of independent colleges, the management organization is basically perfect. The assignment of responsibility from senior leaders to specific management personnel in laboratory is relatively clear. The management system is sound. In addition, in order to reach the requirements 
of indicators of teaching evaluation, it normalizes all kinds of work. Through learning other colleges and referring to experience of their own, and integrating practical situation of themselves, they introduce a lot of rules and regulations, which involve relatively complete aspects and ensure the construction and management of laboratory has rules to follow. The team of technical personnel in laboratory has been complete basically and it mainly focuses on young people. Therefore, in the implementation of daily work, they have skyscraping spirit of utter devotion and relatively high enthusiasm and guarantee the operation of laboratory very well.

On the whole, the construction and management of laboratory in independent colleges is good and can meet the requirements of implementation of undergraduate teaching at present well to provide guarantee for experiment teaching.

\section{PROBLEMS EXISTING IN CONSTRUCTION AND MANAGEMENT OF LABORATORY UNDER THE SITUATION OF INNOVATION AND ENTREPRENEURSHIP}

Because independent colleges have no fiscal appropriation from the country and mainly raise funds by investors through various ways, the financial resources are limited. The initial stage planning of laboratory construction is not long-term and centers on meeting the requirements of undergraduate teaching. The condition of laboratory cannot meet further requirements of innovation and enterprise education, technological innovation and social services. Some laboratories adopt the way of construction according to requirements at earlier stage. The use ratio is relatively low when carrying out undergraduate teaching. At present, the space of laboratory construction is limited. The experimental sites and facilities are platform and carrier of innovation and entrepreneurship education for college students. It is very difficult to expand laboratory especially for innovation and entrepreneurship education.

After laboratory instruments and equipment come into use for the cycle of ten years, it is increasingly obvious that the instruments and equipment are outdated, aged and backward. The cost of later-stage maintenance grows with each passing day. Besides, the expenditure of investors of colleges is limited. It boosts pressure on investors to put large-scale investment in purchasing and updating instruments and equipment. They have more concerns from the perspective of benefit and cannot purchase large-scale laboratory equipment for innovation and entrepreneurship education. Therefore, the practical teaching of innovation and entrepreneurship education must be carried out on the basis of existing equipment in laboratory. However, the instruments and equipment in laboratory cannot keep pace with the progress of social science and technology and meet the requirements of innovation and entrepreneurship education.

In the process of construction of rules and regulations in colleges, some of them are drafted temporarily and formed according to experience of colleges and practical situation of themselves. Seen from the outside, the rules and regulations of management are relatively sound. Because the time is not enough, it is limited to consider problems. In addition, some files have no reference value. After development of a period of time and new requirements for colleges under the environment of innovation and entrepreneurship education, it often appears the situation that some rules and regulations have inadequate consideration and many loopholes.

The team of experiment technicians has reached the choke point of development and promotion. It is in urgent need of construction. On one hand, the team of experimental and technical talents with young people as the principal part has been mature gradually. Their dedication spirit and enthusiasm reduce gradually. Especially excellent talents need further development. But just as all other colleges, the technological and academic level of experiment technicians is relatively low. They cannot receive attention in the long run. The incentive mechanism is limited. The post cannot meet the fast growing requirements of laboratory and instruments and equipment. On the other hand, the innovation and entrepreneurship education puts forward higher requirements for technological level of experiment and technical talents team. In the face of practical teaching of innovation and entrepreneurship education, there are few interdisciplinary talents with broad scope of knowledge. And the source of them is single. The existing personnel cannot meet the requirements for cultivation of innovational and enterprising talents. [5]- [7]

\section{PROMOTE THE CONSTRUCTION OF LABORATORY WITH THE HELP OF INNOVATION AND ENTREPRENEURSHIP EDUCATION}

In 2015, the State Council issued the Opinion on Deepening the Implementation of Innovation and Entrepreneurship Education Reform for Institution of Higher Learning. It puts forward clear requirements for strengthening innovation and entrepreneurship education of colleges. In main tasks and measures, it puts forward strengthening the laboratory construction in colleges and using resources in colleges to serve innovation and entrepreneurship education. Local governments introduce policies in succession to support the establishment of innovation and entrepreneurship in colleges. Colleges also carry out relevant work one after another according to requirements. Laboratory construction obtains good development opportunity under this situation.

\section{A. Obtain Capital Source through Government Channels}

Independent colleges need to break through the dilemma that the one-sided capital investment of laboratory construction is limited and difficulties exist in raising funds from many aspects and timely understand policies and information of local governments. The policies in many places are different. It is necessary to be ready at all times to seize the opportunity to obtain funds. For example, in 2014, Guangdong province introduced the policy of "Engineering of Strong School with Innovation", providing good opportunity for local independent colleges to obtain considerable funds.

\section{B. Build Diversified and High-Level Experiment and Technical Talents Team}

The practical teaching of innovation and entrepreneurship education puts forward higher requirements for experiment technicians and receives high attention of schools. The construction of experiment and technical talents team benefits 
from it. On one hand, introduce high-level professional and technical talents outside school into the laboratory. On the other hand, it is necessary to seize the opportunity that schools pay attention to, strengthen the cultivation and development of talents, take the cultivation strategy for talents of "walking out and introducing into", participate in guiding innovation and entrepreneurship program to give play to level of their own; integrate teachers on campus and invite experts off-campus to train; organize them to go out to learn, exchange and gain upto-date practical technique; establish proper qualification evaluation system, timely investigate working condition of experiment technicians, timely put forward reform and correction for deficiencies existed in work, improve overall vocational level and quality of service; improve incentive system.

\section{Make Full Use of Laboratory and Excavate Potential of Teaching Instruments and Equipment}

Experimental project of innovation and entrepreneurship designs cross-specialty laboratory. Some specialized laboratories at present can only be used by students of this specialty, in order to further improve the use ratio of laboratory. In the process of innovation and entrepreneurship practice of college students, the laboratory projects that extend continuously give play to function of laboratory equipment and excavate the potential of equipment to a greater degree.

\section{Promote Information Construction of Laboratory}

In practice course of innovation and entrepreneurship education for college students, designing experiments will increase greatly with complicated and overloaded functional requirements. Information data such as functions of laboratory and instruments and equipment through information platform of laboratory can make full use of laboratory and better give full play to the effect of opening laboratory. Collecting and summarizing laboratory data through information platform can liberate management personnel from multifarious work that provide laboratory data to national, provincial and municipal superior departments annually, letting them put more energy and time into improving the quality of laboratory management.

\section{Pay Close AtTEntion to Connotative

Under the strategic target that independent colleges carry out connotative development, laboratories can tease integrally from aspects such as management system, construction procedures, normalization, utilization of instruments and equipment, safety construction and management of laboratory according to situation of their own, and implement gradually, coordinate with colleges to complete the transformation of connotative development, in order to better provide service for innovation and entrepreneurship education.

Further standardize management system. Colleges clearly divide responsibilities and functions of leader in charge, functional departments and experiment technicians, further improve mechanism, striving to reaching efficient system that leaders in charge of colleges guide, competent functional departments carry out and experiment technicians implement. Integrally tease rules and regulations that have been introduced, further modify according to practical situation, make up for deficiency, systematically connect measures such as supervision, implementation, inspection, rectification, reward and punishment in rules and regulations, make laboratory management link, restrict and supervise mutually and make the management work of laboratory form a perfect body of virtuous circle.

Carry out standardized management of laboratory construction, standardize and normalize all links such as declaration, examination, approval and execution of the whole construction. For the new construction, reconstruction and teaching instruments and equipment of new laboratory, take academic year as a cycle. In the second term of each academic year, according to teaching situation of next academic year, the whole school uniformly organizes the declaration of purchase plan, fills in unified application materials with normalization and ensures the purchase plan is necessary, scientific and high efficient through demonstration of end-user and experts on and off campus.

Strengthen the management of low priced and easily worn articles, take semester as a cycle, and uniformly organize declaration and purchasing, avoid the waste of low priced and easily worn articles because of long-term large number of overstock and alteration of experimental project, further supervise and urge the utilization of low priced and easily worn articles.

Follow the principle that makes the best use of everything and improve the utilization of equipment from many aspects. On one hand, improve the utilization of public equipment. For public equipment such as computers, the configuration of computer in general laboratory is relatively high. It will not meet the requirements of teaching software in laboratory for hardware within three to five years and they need update. Because administrative-office has not high requirements for equipment and the machine is also too old, it is feasible to replace computers in laboratory for administrative-office to use, which can save some capitals for administrative-office. On the other hand, reuse obsolete and scrapped equipment. Because some equipment have been purchased for ten years and entered the period of elimination, reuse and reserve some spare and accessory parts in good condition on scrapped equipment for laboratories to carry out experiment teaching and innovation and entrepreneurship education and excavate function of equipment.

The safety construction and management of laboratory is one of the key works of laboratory. On one hand, the safe operation of laboratory ensures that teachers and students can have personal safety when carrying out experiment and the property of colleges avoids loss; on the other hand, in the educational process of safe operation of laboratory, students can form good safety awareness and safe standard of behavior of experiment operation. After the talents trained enter and serve the society, they can further influence and improve the safety level of the whole society. Therefore, the safety construction and management of laboratory cannot be 
neglected. It is necessary to carry out safety construction and management of laboratory through thoroughly implementing the principles that "center on prevention, implement at every level and directors take the responsibility". The safety construction and management of laboratory adopts construction of index type and ensures normalization and feasibility of safety construction and management of laboratory. At present, our country hasn't introduced documents related to laboratory safety. In 2014, Guangdong province introduced documents related to safety construction and management of laboratory and defined indexes of various work in safety construction and management and revised again in 2015. Therefore, the index type of safety construction and management of laboratory is feasible.

\section{CONCLUSION}

To sum up, in consideration of the fact that the capital introduced later becomes more and more, students who participate in involving broader and broader aspects, and implementation of innovation and entrepreneurship education in laboratory, the construction of laboratory in independent colleges needs to consider continuity. When adding equipment, it is necessary to have feasible update plan and adhere to the principle of sustainable development. In addition, it shall also grasp the direction of development, seize all kinds of good opportunities outside school, make use of off-campus resources and reasonably use each sum of money to serve the construction of laboratory as far as possible. With the deepening of innovation and entrepreneurship education, it needs to continuously explore how to better exert the supporting and service function of laboratory, in order to further let innovation and entrepreneurship and construction and management of laboratory promote each other.

\section{REFERENCES}

[1] Hong Jiafen. Exploration on Construction Model of Laboratory in Independent College Based on Project Management [J], Research and Exploration in Laboratory, 2015.32 (1): 162-164.

[2] Wang Zhi, Du Yunhai, Liu Wenwen. Discussion on Construction of Laboratory in Colleges from Innovation of College Students [J], Research and Exploration in Laboratory, 2013, 32(6): 287-289.

[3] Chen Weide. Construction and Research on Laboratory in Independent College [J], Experimental Technology and Management, 2010,27(12): 218-220.

[4] Wu Yujian. Dilemma of Reform of Innovation and Entrepreneurship Education in College and Path Selection [J], Education Exploration, 2015, (11): 63-66

[5] Ou Yanfei, Luo Jianliang, Chen Xiaolan, Ben Yi, Zhao Kaige, Feng Dongmei, Zhou Yiqin, Zhang Yong. Function of Laboratory Qualification Authentication System in Talent Team Construction of Laboratory in Colleges [J], Experimental Technology and Management, 2013.30 (3): 175-179.

[6] Zhao Lanyu, Liu Xin. Research on Cultivation System of Talents of Innovation and Entrepreneurship Education in Independent Colleges [J], Exploration on Educational Theory, 2014. (14) : 3-4.

[7] Huang Xinghai. Analysis on Practice Teaching Mechanism of Innovation and Entrepreneurship Education in Colleges $[\mathrm{J}]$, Heilongjiang Researches on Higher Education, 2015. (11) : 122-124. 